\title{
LOW-TEMPERATURE DIRECTED INTERESTERIFICATION INCREASES TRIUNSATURATED AND TRISATURATED TRIACYLGLYCEROLS OF PALM OIL AND AFFECTS ITS THERMAL, POLYMORPHIC AND MICROSTRUCTURAL PROPERTIES
}

\author{
NOOR LIDA HABI MAT DIAN*; LEE YEE YING**; NIK MOHD AZNIZAN NIK IBRAHIM*; \\ NORAZURA AILA MOHD HASSIM*; SAW MEI HUEY*; TAN CHIN PING ${ }^{\star}$ and LAI OI MING
}

\begin{abstract}
Directed interesterification (DIE) is an interesterification technique performed at a sufficiently low temperature to allow higher melting triacylglycerols (TAG) to crystallise out as they are formed during the reaction. Thus, DIE is an excellent tool for changing the TAG composition of oils and fats and consequently extends their applications. DIE converts liquid oils into plastic fats, reduces the formation of graininess and improves the plasticity of lard, and increases the unsaturation level of the olein fraction of fats. This study explored the possibility of using lipase-catalysed DIE (EDIE) as a 'green' technique to produce palm oil $(P O)$ which is high in triunsaturated $\left(U_{3}\right)$ and trisaturated $\left(S_{3}\right) T A G$, which in turn, when fractionated, produce an olein fraction which is high in unsaturated (especially, oleic acid) and a stearin fraction that is high in saturated (especially, palmitic acid) fatty acids. EDIE resulted in a significant $(p<0.05)$ increase in $U_{3}$ and $S_{3} T A G$ of $P O$, from $4.3 \%$ and $5.2 \%$ before EDIE to $27.6 \%$ and $31.9 \%$ after EDIE, respectively. The increased content of $U_{3}$ and $S_{3} T A G$ subsequently altered the physical properties of PO. Higher $U_{3} T A G$ content led to an increase in the proportion of the low melting fraction of $P O$. Meanwhile, the melting point, solid fat content at all temperatures and the proportion of high melting fraction of PO show to increase following the rise in $S_{3}$ TAG after EDIE. A differential scanning calorimetry melting curve showed that the low and high melting fractions of EDIE PO were distinctively separated, indicating ease of fractionation. EDIE also increased the proportion of $\beta$ crystals in PO. Thus, its microscopic structure showed dense crystal aggregates with a coarse plate-like and orderly packed structure.
\end{abstract}

Keywords: palm oil, directed interesterification, triacylglycerol, thermal profile, polymorphic behaviour, microscopic structure.

Date received: 7 August 2018; Sent for revision: 9 August 2018; Received in final form: 24 September 2018; Accepted: 17 December 2018.

\footnotetext{
* Malaysian Palm Oil Board,

6 Persiaran Institusi, Bandar Baru Bangi,

43000 Kajang, Selangor, Malaysia.

E-mail: nlida@mpob.gov.my

** School of Science, Monash University Malaysia,

Jalan Lagoon Selatan, Bandar Sunway,

47500 Subang Jaya, Selangor, Malaysia.

‡ Department of Food Technology, Faculty of Food Science and Technology, Universiti Putra Malaysia, 43400 UPM Serdang, Selangor, Malaysia.

抹 Department of Bioprocess Technology, Faculty of Biotechnology and Biomolecular Sciences, Universiti Putra Malaysia, 43400 UPM Serdang, Selangor, Malaysia.
}

\section{INTRODUCTION}

Interesterification (IE) is an important technique currently employed to modify the physicochemical characteristics of oils and fats. IE can take place within individual triacylglycerols (TAG) (intraesterification) or between TAG (interesterification) molecules. IE randomises the fatty acids (FA) at the $s n-1, s n-2$ and $s n-3$ positions (by a non-specific catalyst), or only at the sn-1 and $s n-3$ positions (by an $s n-1,3$ stereospecific 
catalyst, normally a lipase). Consequently, IE modifies the TAG composition which in turn alters physical characteristics such as crystallisation and melting behaviour, solid content and polymorphic behaviour of the oils and fats (Amir et al., 2012).

Typically, IE is conducted at a temperature of around $100^{\circ} \mathrm{C}-120^{\circ} \mathrm{C}$ for chemical IE (CIE), and $55^{\circ} \mathrm{C}-70^{\circ} \mathrm{C}$ for enzymatic IE (EIE). At these temperatures, all lipids are completely liquefied, and the reactions are, therefore, accomplished in a single liquid phase. Directed IE (DIE) is performed similarly, but at a much lower temperature, i.e., below the temperature of the highest melting TAG (normally below $50^{\circ} \mathrm{C}$ ) (De Lathauwer et al., 1983). This allows the high melting (more saturated) TAG, which are normally trisaturated $\left(S_{3}\right)$, to crystallise as they form. The crystallised $S_{3}$ TAG will then be withdrawn from the reaction system (liquid phase) because in the crystallised form, they can no longer take part in the reaction. Such selective crystallisation disrupts the equilibrium system. To re-establish the reaction equilibrium, new $S_{3}$ TAG are continuously formed from the remaining liquid phase, which in turn also precipitate out. The formation and crystallisation of $S_{3}$ TAG continue until all TAG capable of crystallising have been eliminated from the reaction phase (Placek and Holman, 1957; Rousseau and Marangoni, 2008), or until the reaction is stopped. Segregation of saturated FA (SAFA) into $S_{3}$ TAG is accompanied by a corresponding tendency for unsaturated FA (USAFA) to form triunsaturated $\left(\mathrm{U}_{3}\right)$ TAG. DIE eventually results in a lipid mixture that contains a high proportion of $S_{3}$ and $U_{3}$ TAG, at the expense of disaturated $\left(\mathrm{S}_{2} \mathrm{U}\right)$ and diunsaturated $\left(\mathrm{U}_{2} \mathrm{~S}\right)$ TAG (De Lathauwer et al., 1983; Placek and Holman, 1957).

DIE increases $\mathrm{U}_{3}$ and $\mathrm{S}_{3}$ TAG of lard (Rousseau and Marangoni, 2008; Chobanov and Topalova, 1979), tallow (MacKenzie and Stevenson, 1995) and palm oil (PO) (Lago and Hartman, 1986; Laning, 1985). Chemical DIE increases $U_{3}$ and $S_{3}$ TAG of PO to $12 \%$ and $30 \%$, respectively (Laning, 1985). The olein and stearin fractions obtained from chemically DIEed PO are composed of about $75 \% \mathrm{U}_{3}$ and $62 \%$ $\mathrm{S}_{3}$ TAG, respectively (Lago and Hartman, 1986). The ability of DIE to increase $\mathrm{U}_{3}$ and $\mathrm{S}_{3}$ TAG of oils and fats has been applied as a useful technique to change the physical characteristics of certain fats, making them more feasible for particular applications. DIE converts liquid oils into plastic fats (De Lathauwer et al., 1983), reduces the formation of graininess and improves the plasticity of lard (MacKenzie and Stevenson, 1995), increases the unsaturation level of the olein fraction of certain fats (MacKenzie and Stevenson, 2000), and produces oils and fats that are high in monoacylglycerols (MAG) and diacylglycerols (DAG) (Baur and Lange, 1951).
Production of structured lipid containing medium chain SAFA and USAFA directly from coconut oil through DIE in a solvent has been reported by Nugrahini and Soerawidjaja (2015).

Evidence of effects of enzymatic DIE (EDIE) on the physico-chemical characteristics of $\mathrm{PO}$ is as yet unavailable. Hence, the present study was carried out to evaluate the physico-chemical changes in PO after EDIE. It is expected that utilising this 'green' EDIE process on PO (which consists of equal amounts of USAFA, mainly oleic, and SAFA, mainly, palmitic) will result in $\mathrm{PO}$ which is high in $\mathrm{U}_{3}$ and $\mathrm{S}_{3}$ TAG. Such PO is desirable, especially when the oil is subjected to fractionation, as it will produce an olein fraction which is high in USAFA and a stearin fraction that is high in SAFA, that is relatively much higher than the USAFA and SAFA content of olein and stearin fractions of refined, bleached and deodourised (RBD) PO. Both fractions have good potential to be used as oils and fats for healthy foods. The high oleic olein fraction could be used as a healthy high oleic frying or salad oil. The high SAFA stearin fractions could be used as an excellent alternative to trans fats. When blended or restructured with other vegetable oils via IE, and texturised, they could produce a trans-free hardstock with excellent oil binding capacity and could also perform effectively as a structural fat in formulating trans-free reduced saturated solid fat products.

\section{MATERIALS AND METHODS}

\section{Materials}

RBD PO was procured from Keck Seng (M) Berhad (Johor, Malaysia). Commercial immobilised Thermomyces lanuginosus lipase (Lipozyme TLIM) was purchased from Novozymes A/S (Bagsvaerd, Denmark). The TAG standards used for elucidation of the TAG species were purchased from Sigma Aldrich Inc. (Sigma Chemical Co., USA). All chemicals and solvents were of analytical and high performance liquid chromatography (HPLC) grades, respectively.

\section{Lipozyme TLIM Lipase Conditioning}

Pre-conditioning of the immobilised lipase was carried out to remove any extra moisture before conducting EDIE of PO. Immobilised enzymes normally contain approximately $5 \%(\mathrm{w} / \mathrm{w})$ of water, which need to be removed to prevent hydrolysis of the oil substrate which will lead to the formation of undesirable free FA (FFA) and partial glycerides such as MAG and DAG (Saw et al., 2009). Lipozyme TLIM lipase was conditioned by reacting the lipase $(10 \% \mathrm{w} / \mathrm{w})$ with $\mathrm{PO}$ at $70^{\circ} \mathrm{C}$ for $30 \mathrm{~min}$ before draining the PO from the reaction system. This step 
was repeated five times with fresh RBD PO. After the fifth reaction, the reacted PO contained only about $3 \%$ FFA as compared to $18 \%$ FFA in the reacted PO from the initial reaction. The FFA was assessed by a titration method defined in the AOCS Official Method Ca 5a-40 (Firestone, 2009). The FFA was expressed as the percentage of palmitic acid. The treated enzyme was then used for the subsequent EDIE reaction.

\section{EDIE of PO}

Moisture-free PO was accurately weighed and melted at $80^{\circ} \mathrm{C}$ for $45 \mathrm{~min}$ in a double-jacketed and temperature-controlled stirred tank vessel under vacuum. The temperature was then lowered to $30.0^{\circ} \mathrm{C}$ before the addition of $10.0 \%(\mathrm{w} / \mathrm{w})$ of preconditioned Lipozyme TLIM lipase. The mixture was left to react for $18.0 \mathrm{hr}$ under stirring at 500 rpm. The reaction was then stopped by rapidly heating the reaction mixture to a high temperature in a microwave oven before being vacuum-filtered to separate the enzyme particles from the lipid mixture.

\section{Purification of Crude Enzymatically Directed Interesterified PO (EDIE PO)}

The enzyme-free EDIE PO comprising TAG and by-products (a mixture of FFA, MAG and DAG) was subjected to purification before further analysis. Purification was performed using a shortpath distillation (SPD) unit (KD6 System, UIC $\mathrm{GmbH}$, Alzenau-Hörstein, Germany) in a twostep process, according to the method reported by Saberi et al. (2012). FFA and MAG were removed in the first step. The residue (a mixture of DAG and TAG) was purified again to remove DAG. The same conditions were used for both purification steps: evaporator vacuum of 0.001 mbar, feeding rate of 1.3 litres $\mathrm{hr}^{-1}$, condenser temperature of $85^{\circ} \mathrm{C}$, feeding tank temperature of $75^{\circ} \mathrm{C}$, and roller speed of 280 $\mathrm{rpm}$. Evaporation temperature employed in the first and second purification steps was $200^{\circ} \mathrm{C}$ and $250^{\circ} \mathrm{C}$, respectively.

\section{Fatty Acid Composition (FAC)}

FAC was determined as FA methyl esters (FAME) according to the MPOB Test Method p3.5:2004 (MPOB, 2004), which is technically equivalent to ISO 5508:1990(E) (IOS, 1990). FAME was prepared by dissolving $50 \mathrm{mg}$ of a melted and homogenised fat blend in $950 \mu \mathrm{l}$ hexane, and $50 \mu \mathrm{l}$ of $1 \mathrm{M}$ sodium methoxide. The mixture was then mixed vigorously with a vortex mixer for $10 \mathrm{~s}$ or until it became cloudy before centrifugation at $2000 \mathrm{rpm}$ for $2 \mathrm{~min}$ to separate the mixture into two distinct layers. The upper clear supernatant consisting of
FAME was decanted. One $\mu \mathrm{l}$ of the FAME was then injected and analysed using a Hewlett Packard HP 6890 Series (Palo Alto, USA) gas chromatography system equipped with a flame ionisation detector. Separation was performed using a Durabond DB-23 fused silica capillary column (60 m length $x 0.25 \mathrm{~mm}$ i.d. x $0.25 \mu \mathrm{m}$ film thickness) (Agilent, Santa Clara, USA). Injector and detector temperatures were set at $240^{\circ} \mathrm{C}$, whereas the column temperature was isothermal at $185^{\circ} \mathrm{C}$. The flow rate of the carrier gas helium was $0.8 \mathrm{ml} \mathrm{min} \mathrm{m}^{-1}$. Peaks were identified by FAME standards and quantified using the peak area normalisation method.

\section{TAG Composition}

TAG composition was determined using Waters HPLC Model Alliance e2695 (Waters, United Kingdom) equipped with Waters ELSD model ELSD 2424. A Merck KGaA column (Darmstadt, Germany) Purospher ${ }^{\circledR}$ Star RP-18e $(250 \mathrm{~mm} \times 4$ $\mathrm{mm}$ ) with $5 \mu \mathrm{m}$ particle size was used to separate the TAG. The column temperature was set at $35^{\circ} \mathrm{C}$. The sample was melted at $70^{\circ} \mathrm{C}$, dissolved in acetone at a concentration of $10 \%(\mathrm{v} / \mathrm{v})(100 \mu \mathrm{l}$ of sample into $900 \mu \mathrm{l}$ of acetone) and filtered through a $0.2 \mu \mathrm{m}$ PTFE membrane filter to remove impurities. A $10 \mu \mathrm{l}$ sample was then injected into the column. Separation was carried out with a mobile phase containing a mixture of acetone and acetonitrile (Merck, Darmstadt, Germany) at a gradient composition of $35 \%, 65 \%, 85 \%, 35 \%$ and $35 \%$ of acetone at $0,10,15$, 20 and $25 \mathrm{~min}$, respectively. The mobile phase flow rate was set at $1.5 \mathrm{ml} \mathrm{min}^{-1}$ with a total run time of 25 min. Individual chromatographic TAG peaks were identified by comparing peak elution time with those of the TAG standard (OLL, OLO, OOO, PMP, PPP, PPS, PLL, PLO, POO, SOO, PLP, POP and POS) and quantified using the peak area normalisation method.

\section{Differential Scanning Calorimetry (DSC) Thermal Behaviour}

DSC thermal behaviour was studied using a differential scanning calorimeter, DSC 7 (Perkin Elmer, Boston, MA). Approximately 7-8 mg ( \pm 0.005 $\mathrm{mg}$ ) of a precisely weighed molten sample was placed in a hermetically sealed DSC pan. The fat sample was held at $80^{\circ} \mathrm{C}$ for $10 \mathrm{~min}$ to erase its thermal memory. The sample was then cooled to $-60^{\circ} \mathrm{C}$ at a cooling rate of $-25^{\circ} \mathrm{C} \mathrm{min}^{-1}$, and held at this temperature for another $10 \mathrm{~min}$. The melting thermogram of the sample was then recorded by heating the sample from $-60^{\circ} \mathrm{C}$ to $80^{\circ} \mathrm{C}$ at a heating rate of $5^{\circ} \mathrm{C} \mathrm{min}^{-1}$. The sample was then held at $80^{\circ} \mathrm{C}$ for $10 \mathrm{~min}$, and cooled to $-40^{\circ} \mathrm{C}$ at a cooling rate of $5^{\circ} \mathrm{C} \min ^{-1}$ to determine crystallisation behaviour. Total $\left(\Delta \mathrm{H}_{\mathrm{f}}\right)$ and partial $\left(\Delta \mathrm{H}_{\mathrm{i}^{\circ} \mathrm{C}}\right)$ melting enthalpy, 
and total $\left(-\Delta \mathrm{H}_{\mathrm{f}}\right)$ and partial $\left(-\Delta \mathrm{H}_{\mathrm{i}^{\circ} \mathrm{C}}\right)$ crystallisation enthalpy, at various temperatures were calculated using the DSC Data Analysis software.

\section{Solid Fat Content (SFC)}

SFC was determined with a Bruker Minispec MQ20 pulsed nuclear magnetic resonance ( $p-N M R$ ) analyser (Karlsruhe, Germany) according to the MPOB Test Method p4.8:2004-Non-stabilised Serial procedures (MPOB, 2004), which is technically equivalent to MS 817: Part 9 Section 1:2003 (MS, 2003). Molten sample was filled up to $3 \mathrm{~cm}$ height of a p-NMR tube, re-melted at $70^{\circ} \mathrm{C}$ for $30 \mathrm{~min}$, chilled at $0^{\circ} \mathrm{C}$ for $90 \mathrm{~min}$, and held at the respective measuring temperatures for $30 \mathrm{~min}$ prior to measurement of total solid fat $(\%)$ at each measuring temperature from $5^{\circ} \mathrm{C}-50^{\circ} \mathrm{C}$ at intervals of $5^{\circ} \mathrm{C}$.

\section{Slip Melting Point (SMP)}

SMP of the sample was determined according to the MPOB Test Method p4.2:2004 (MPOB, 2004), which originated from the AOCS Official Method Cc 3-25 (Firestone, 2009). A molten sample was placed in three capillary tubes (50-60 mm length $x$ 1.1-1.3 mm i.d. x 1.4-1.5 e.d.) with openings at both ends, filling each to a length of $10 \mathrm{~mm}$. The sample in the tube was then solidified by rolling the tube on an ice cube. The capillary tube was then placed in a test tube, and held in a water bath equilibrated at $10^{\circ} \mathrm{C}$ for 16 hr. The tube was then attached to a thermometer (graduated in divisions of $0.1^{\circ} \mathrm{C}-0.2^{\circ} \mathrm{C}$ ) with a rubber band, before immersing both into a beaker containing $400 \mathrm{ml}$ of cold distilled water with a temperature of $5^{\circ} \mathrm{C}-10^{\circ} \mathrm{C}$ below the expected SMP of the sample. The water bath was agitated with a magnetic stirrer, and heat was applied continuously to increase the bath temperature at a rate of $0.5^{\circ} \mathrm{C} \mathrm{min}{ }^{-1}$. The temperature at which the fat column rose due to hydrostatic pressure was recorded as SMP of the fat sample.

\section{Polymorphic Behaviour}

Polymorphic forms of the fat crystals were determined using a Rigaku TTRAX III X-Ray diffractometer (Rigaku Inc, Tokyo, Japan). Fat sample was melted at $70^{\circ} \mathrm{C}$ for $30 \mathrm{~min}$ to erase the crystal memory. Subsequently, a small amount of the molten sample was placed in the $\mathrm{X}$-ray sample pan and stored for $24 \mathrm{hr}$ at $5^{\circ} \mathrm{C}, 10^{\circ} \mathrm{C}, 15^{\circ} \mathrm{C}, 20^{\circ} \mathrm{C}, 25^{\circ} \mathrm{C}$ and $30^{\circ} \mathrm{C}$, prior to determination of the polymorphic form. The short spacings of the $\beta^{\prime}$ form are at 4.2 and $3.8 \AA$ and that of the $\beta$ form is at $4.6 \AA$. The levels of $\beta^{\prime}$ and $\beta$ crystals in the sample were estimated by the relative intensities of the short spacings at 4.2 and $3.8 \AA$, and at $4.6 \AA$ (D'Souza et al., 1990).

\section{Microstructure}

The microstructure of the fat crystals was determined using a polarised light microscope (PLM). A small droplet (about $10 \mu \mathrm{l}$ ) of molten fat was placed on a glass slide and covered with a glass slip, and then rapidly cooled to $5^{\circ} \mathrm{C}, 10^{\circ} \mathrm{C}$, $15^{\circ} \mathrm{C}, 20^{\circ} \mathrm{C}$ and $25^{\circ} \mathrm{C}$. The sample was stabilised at each temperature for $24 \mathrm{hr}$ before measurement. A Leica DMLP polarised light microscope (Leica, Germany), equipped with a Linkam THMS 600 temperature controller stage and a JVC 3-CCD colour video camera, was used. Temperature was thermostatically controlled by a Linkam TP 94 multi-ramp temperature programmer and an LNP automatic cooling system (Linkam, United Kingdom). Liquid nitrogen was used as the coolant. A photomicrograph of the crystal was taken at 200X magnification.

\section{Statistical Analysis}

Statistical analysis was conducted on triplicate measurements. Data were analysed with one-way analysis of variance (ANOVA), using the Minitab 16 (Minitab Inc, State College, PA, USA) statistical software. Data were expressed as means with standard deviations. Statistical significance was determined using Tukey's test at $p<0.05$.

\section{RESULTS AND DISCUSSION}

\section{Purification of Crude EDIE PO}

Purification of crude EDIE PO was done to remove the by-products (FFA, DAG and MAG) formed during the EDIE process. For a fair comparison, RBD PO was also purified. Purification of the crude EDIE PO is particularly vital as it contains about $20 \%$ by-products that will affect the quality and shelf-life of the EDIE oil. Purification by SPD resulted in EDIE PO and RBD PO with minute amounts of FFA, MAG and DAG.

\section{FA and TAG Composition}

The EDIE process resulted in restructuring the FA distribution in TAG molecules. Table 1a shows the effect of EDIE on the FAC of PO. Following EDIE, a significant reduction in USAFA and a significant increase in the SAFA content of PO were observed. Small changes in FAC after EDIE were expected due to the removal of FFA, MAG and DAG from crude EDIE PO during the purification process. Reduction in USAFA and increase in the SAFA content after EDIE might be because, during EDIE, USAFA rather than SAFA was preferentially detached from the TAG molecules. Hence, there was more USAFA 


\begin{tabular}{|c|c|c|}
\hline Characteristic & RBD PO & EDIE PO \\
\hline (a) Fatty acid & \multicolumn{2}{|c|}{ Amount $(\%)$} \\
\hline C12:0 Lauric (La) & $0.2 \pm 0.01^{\mathrm{a}}$ & $0.2 \pm 0.06^{\mathrm{a}}$ \\
\hline C14:0 Myristic (My) & $1.1 \pm 0.05^{\mathrm{a}}$ & $1.1 \pm 0.06^{\mathrm{a}}$ \\
\hline C16:0 Palmitic (P) & $44.3 \pm 0.90^{\mathrm{a}}$ & $47.2 \pm 1.60^{\mathrm{b}}$ \\
\hline C18:0 Stearic (S) & $4.2 \pm 0.05^{\mathrm{a}}$ & $4.2 \pm 0.02^{\mathrm{a}}$ \\
\hline C18:1 Oleic $(\mathrm{O})$ & $41.3 \pm 0.82^{\mathrm{a}}$ & $39.5 \pm 1.52^{\mathrm{a}}$ \\
\hline C18:2 Linoleic (Ln) & $8.9 \pm 0.62^{\mathrm{a}}$ & $7.8 \pm 0.51^{\mathrm{a}}$ \\
\hline Saturated fatty acids (SAFA) & $49.8 \pm 0.98^{\mathrm{a}}$ & $52.7 \pm 0.81^{\mathrm{b}}$ \\
\hline Monounsaturated fatty acids (MUFA) & $41.3 \pm 0.83^{\mathrm{a}}$ & $39.5 \pm 1.54^{\mathrm{a}}$ \\
\hline Polyunsaturated fatty acids (PUFA) & $8.9 \pm 0.62^{\mathrm{a}}$ & $7.8 \pm 0.51^{\mathrm{a}}$ \\
\hline Unsaturated fatty acids (USAFA) & $50.2 \pm 0.56^{\mathrm{a}}$ & $47.3 \pm 0.62^{\mathrm{b}}$ \\
\hline (b) Triacylglycerol & & \\
\hline \multicolumn{3}{|l|}{ Triunsaturated $\left(\mathrm{U}_{3}\right)$} \\
\hline OLL & $0.2 \pm 0.07^{\mathrm{a}}$ & $1.3 \pm 0.14^{\mathrm{b}}$ \\
\hline OLO & $1.4 \pm 0.07^{\mathrm{a}}$ & $9.7 \pm 0.49^{b}$ \\
\hline OOO & $2.7 \pm 0.35^{\mathrm{a}}$ & $16.6 \pm 0.85^{\mathrm{b}}$ \\
\hline Total & $4.3 \pm 0.28^{a}$ & $27.6 \pm 1.06^{b}$ \\
\hline \multicolumn{3}{|l|}{ Trisaturated $\left(\mathrm{S}_{3}\right)$} \\
\hline PMP & $0.5 \pm 0.14^{\mathrm{a}}$ & $1.2 \pm 0.14^{\mathrm{b}}$ \\
\hline РPP & $4.5 \pm 0.21^{\mathrm{a}}$ & $28.1 \pm 0.92^{\mathrm{b}}$ \\
\hline PPS & $0.2 \pm 0.07^{\mathrm{a}}$ & $2.5 \pm 0.42^{\mathrm{b}}$ \\
\hline Total & $5.2 \pm 0.35^{\mathrm{a}}$ & $31.9 \pm 0.97^{b}$ \\
\hline \multicolumn{3}{|l|}{ Diunsaturated-monosaturated $\left(\mathrm{U}_{2} \mathrm{~S}\right)$} \\
\hline PLL & $0.9 \pm 0.14^{\mathrm{a}}$ & $1.5 \pm 0.28^{b}$ \\
\hline PLO & $8.9 \pm 0.21^{\mathrm{a}}$ & $7.7 \pm 0.49^{\mathrm{a}}$ \\
\hline $\mathrm{POO}$ & $27.8 \pm 0.42^{\mathrm{a}}$ & $17.2 \pm 0.64^{\mathrm{b}}$ \\
\hline SOO & $0.6 \pm 0.21^{\mathrm{a}}$ & $0.6 \pm 0.21^{\mathrm{a}}$ \\
\hline Total & $38.2 \pm 0.70^{\mathrm{a}}$ & $27.0 \pm 0.82^{\mathrm{b}}$ \\
\hline \multicolumn{3}{|l|}{ Disaturated-monounsaturated $\left(\mathrm{S}_{2} \mathrm{U}\right)$} \\
\hline PLP & $7.2 \pm 0.64^{\mathrm{a}}$ & $2.1 \pm 0.21^{b}$ \\
\hline POP & $41.1 \pm 0.49^{\mathrm{a}}$ & $10.2 \pm 0.71^{\mathrm{b}}$ \\
\hline POS & $4.0 \pm 0.14^{\mathrm{a}}$ & $1.2 \pm 0.21^{\mathrm{b}}$ \\
\hline Total & $52.3 \pm 1.20^{\mathrm{a}}$ & $13.5 \pm 0.67^{b}$ \\
\hline
\end{tabular}

Note: Means within each row of a similar fatty acid or triacylglycerol (for the two forms of palm oil) bearing different superscript letters are significantly different $(p<0.05)$.

that failed to be repositioned at the MAG and DAG molecules to form new (modified) TAG molecules. Free USAFA was then removed from EDIE PO during the purification process, resulting in the oil having lower USAFA and higher SAFA content than RBD PO.

TAG is a glycerol moiety consisting of three FA esterified to the glycerol backbone. Through IE, FA moieties are shuffled within (intraesterification) and among (IE) the TAG molecules until thermodynamic equilibrium is established (Marangoni and Rousseau, 1995). Therefore, IE of oils and fats, be it random, specific, non-directed or directed, results in the formation of new TAG species (Amir et al., 2012). The TAG structure, as well as the content of SAFA in the TAG itself, will indirectly determine the physical behaviour of the oils and fats, such as the crystal structure, hardness, and plasticity, which subsequently affect the properties of the final product made from the oils and fats (SzydłowskaCzerniak et al., 2005).

There was a substantial change in the TAG composition of PO following EDIE (Figure 1 and Table 1b). The amount of $\mathrm{U}_{3}$ and $\mathrm{S}_{3}$ TAG increased remarkably at the expense of $\mathrm{S}_{2} \mathrm{U}$ and $\mathrm{U}_{2} \mathrm{~S}$ TAG. The highest increase for $\mathrm{U}_{3}$ TAG was in $\mathrm{OOO}$ (6.1-fold) and OLO (6.9-fold), while for $\mathrm{S}_{3}$ TAG, PPP showed the highest increment (6.2-fold), where $O$ is oleic, $L$ is linoleic, and $P$ is palmitic acids. The effect of EDIE on TAG composition of PO is in line with earlier findings on DIE of other oils and fats (Lago and Hartman, 1986; MacKenzie and Stevenson, 2000). The change in the TAG composition of PO as affected by EDIE was reflected in the physical characteristics of $\mathrm{PO}$, e.g., its visual appearance, thermal melting, crystallisation and polymorphic behaviour, and microscopic structure. 


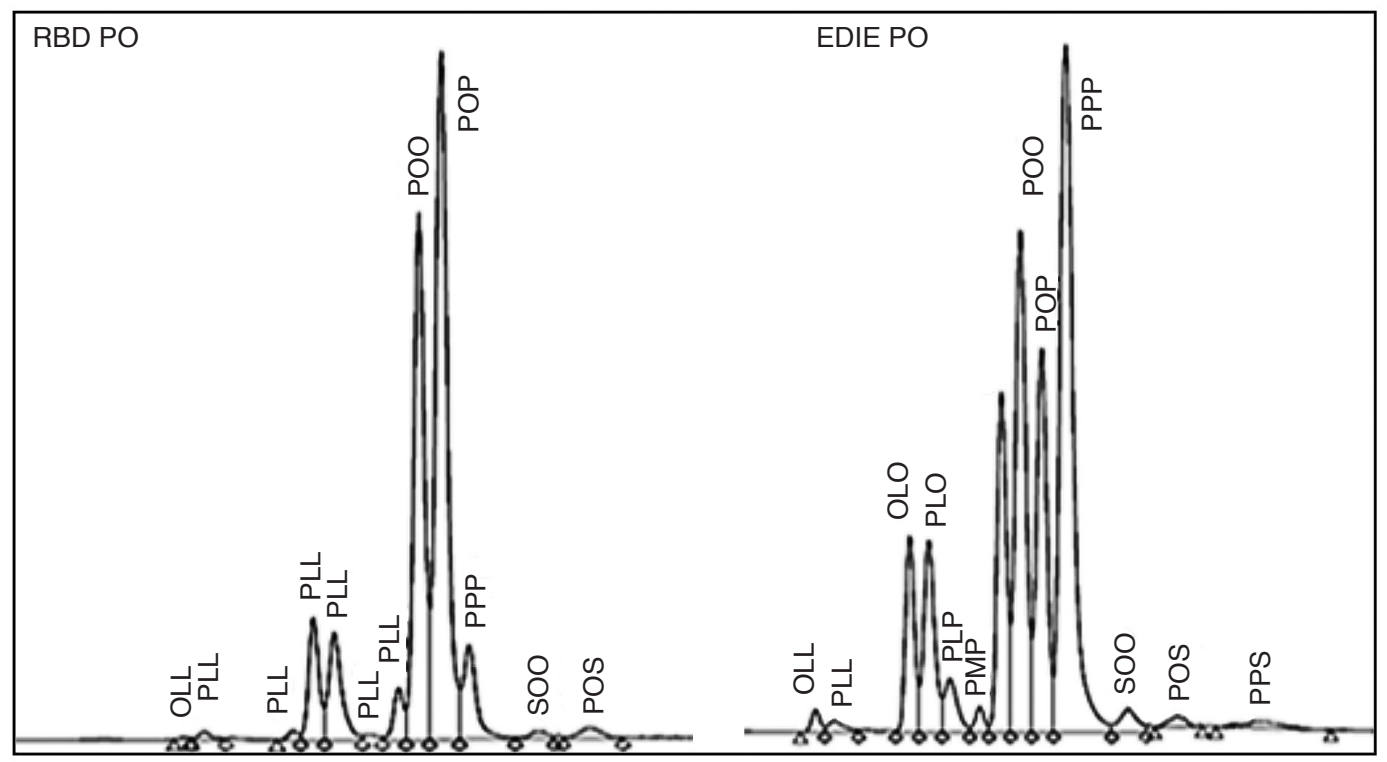

Figure 1. Triacylglycerol chromatograms of enzymatic directed interesterified palm oil (EDIE PO) and refined, bleached and deodourised palm oil (RBD PO).

\section{DSC Melting and Crystallisation Profiles}

DSC is a widely used tool to verify any alteration to the thermal profile of oils and fats by monitoring the changes in melting and crystallisation enthalpies. When a sample is melted or crystallised, the amount of energy absorbed or released will be measured to provide quantitative and qualitative data on endothermic (heat absorption) and exothermic (heat evolution) processes. Changes in the TAG composition of $\mathrm{PO}$ as a result of EDIE is conjoined with alterations to its DSC thermal profiles. The DSC melting profile gives valuable information on the melting behaviour of fats. The $\Delta \mathrm{H}_{\mathrm{f}}$ and $\Delta \mathrm{H}_{\mathrm{i}^{\circ} \mathrm{C}}$ can be used to monitor the physical interaction of fats in blends resulting from thermal changes. DSC $\Delta \mathrm{H}_{\mathrm{f}}$ of an oil or fat represents the amount of energy required to bring the substance from a solid state to a complete melt. Meanwhile, DSC $\Delta \mathrm{H}_{\mathrm{i}^{\circ} \mathrm{C}}$ of an oil or fat is the energy required to bring the substance from a solid state to a partial melt at a specified temperature (Ali and Dimick, 1994). DSC melting thermograms of EDIE PO and RBD PO are shown in Figure 2a. Both thermograms showed two wellseparated components, the low (olein) and high melting (stearin) components, which appear in the low and high temperature endothermic regions, respectively. There were also multiple endotherm peaks with shoulder peaks for both fractions of the fats. The multiple shouldered peaks in the DSC melting profiles of $\mathrm{PO}$ were due to its unique features of complex TAG distribution in PO (Tan and Che' Man, 2002). Melting of TAG complexes occurs simultaneously during heating and, therefore, results in broad or overlapping melting transitions. The highest melting TAG, i.e., $\mathrm{S}_{3^{\prime}}$ melted in the high temperature region, the lowest melting TAG $\left(\mathrm{U}_{3}\right)$ melted in the low temperature region while the intermediate melting TAG $\left(\mathrm{S}_{2} \mathrm{U}\right.$ and $\left.\mathrm{U}_{2} \mathrm{~S}\right)$ melted in between these two extreme regions. The second primary cause of the multiple endotherm peaks is the melting-recrystallisation of the original TAG crystallites and their subsequent melting, which is known as the polymorphism phenomenon or polymorphic transition (Frederick et al., 2008).

The endothermic peak of the low melting component of RBD PO had initial and complete melting temperatures at $-30^{\circ} \mathrm{C}$ and $12^{\circ} \mathrm{C}$, respectively, while that of the high melting component were at about $15^{\circ} \mathrm{C}$ and $42^{\circ} \mathrm{C}$, respectively. The two endothermic peaks of RBD PO are separated by an exothermic peak which appears in the temperature region of $12^{\circ} \mathrm{C}-15^{\circ} \mathrm{C}$, parallel with the findings by Nassu and Gonçalves (1999). The exothermic valley between these two endotherms indicates that significant TAG complex recrystallisation and structural reorganisation (solid-to-solid transformation) occurred during the DSC scans. The endothermic peak in the low temperature region of RBD PO undoubtedly belonged to its low melting $\mathrm{U}_{3}$ and $\mathrm{U}_{2} \mathrm{~S}$ TAG, while the endothermic peak in the high temperature region belonged to the medium $\left(\mathrm{S}_{2} \mathrm{U}\right)$ and high melting $\left(\mathrm{S}_{3}\right)$ TAG of PO. The broad and multiple endothermic peaks of RBD PO were due to its broad TAG distribution (Zhang et al., 2013).

Owing to the altered TAG composition, EDIE PO had a melting curve which was different from that of RBD PO. EDIE PO had two distinct wellseparated low and high temperature endothermic peaks, indicating ease of fractionation. The low and high melting components of EDIE PO showed a major shift in their initial and complete melting 

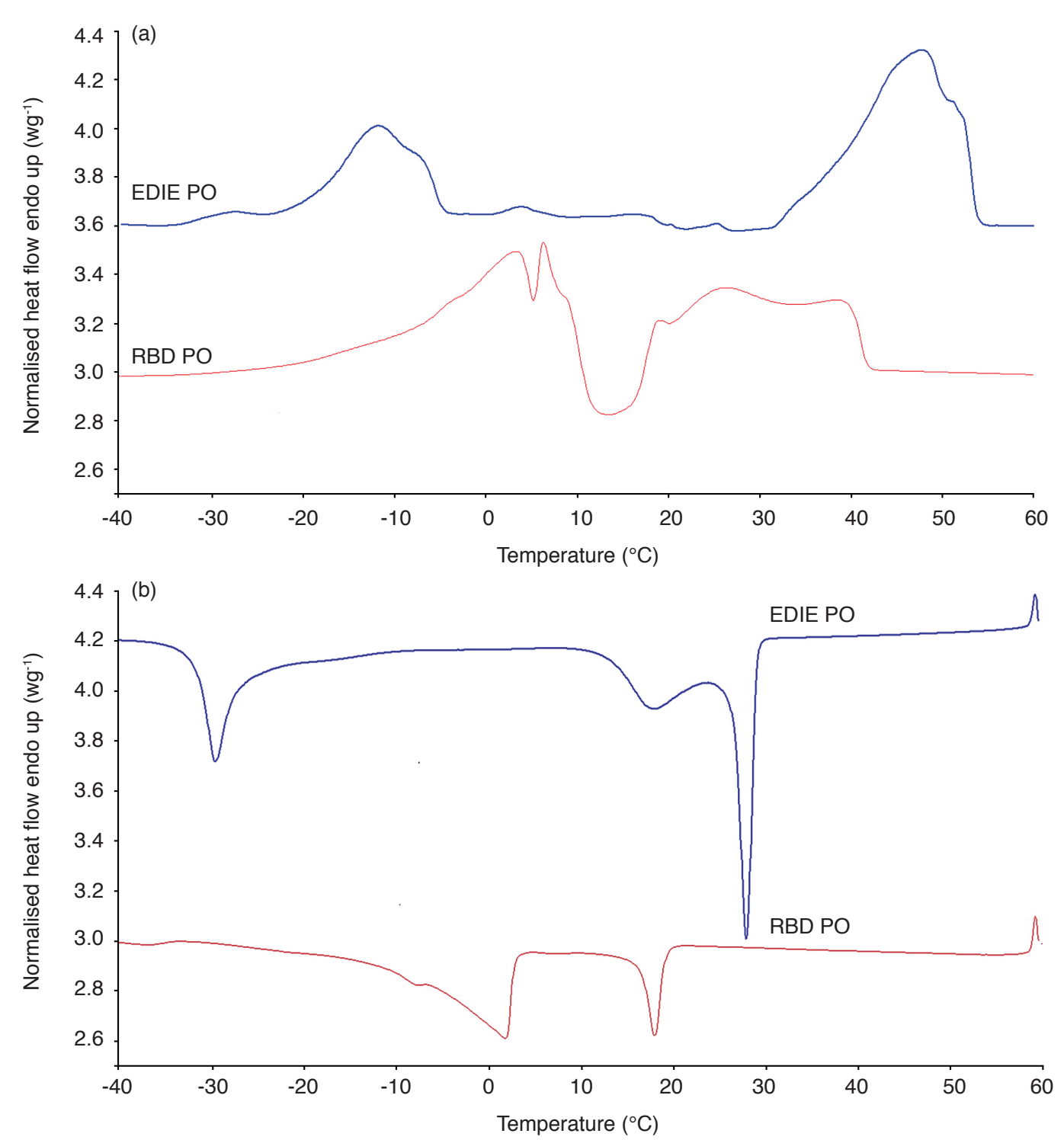

Figure 2. Differential scanning calorimetry melting (a) and crystallisation (b) thermograms of enzymatic directed interesterified palm oil (EDIE PO) and refined, bleached and deodourised palm oil (RBD PO).

temperatures. These melting temperatures of the low melting component shifted towards the lower temperature region, i.e., to $-35^{\circ} \mathrm{C}$ and $-3^{\circ} \mathrm{C}$, respectively, while those of the high melting component shifted to $30^{\circ} \mathrm{C}$ and $55.0^{\circ} \mathrm{C}$, respectively. The transition in the initial and complete melting temperatures as affected by EDIE was due to the formation and accumulation of $\mathrm{U}_{3}$ TAG in the low melting component and $\mathrm{S}_{3}$ TAG in the high melting component, at the expense of $\mathrm{U}_{2} \mathrm{~S}$ and $\mathrm{S}_{2} \mathrm{U}$ TAG. The high temperature endothermic peak of EDIE $\mathrm{PO}$ was broader, taller and sharper, with initial and complete melting temperatures greater than those of RBD PO, due to a greater amount of high melting $\mathrm{S}_{3}$ TAG in EDIE PO than in RBD PO. EDIE PO also exhibited numerous small endothermic peaks in the temperature region of $-3^{\circ} \mathrm{C}$ to $30^{\circ} \mathrm{C}$, which most certainly belonged to the $\mathrm{U}_{2} \mathrm{~S}$ and $\mathrm{S}_{2} \mathrm{U}$ TAG.

DSC $\Delta \mathrm{H}_{\mathrm{f}}$ and $\Delta \mathrm{H}_{\mathrm{i}^{\circ} \mathrm{C}^{\prime}}$ and partial liquid (\%) of EDIE PO and RBD PO at various temperatures are presented in Table 2. Melting enthalpy of EDIE PO and RBD PO corresponded to the melting of the major TAG components present in the oils. Despite having a higher amount of low melting TAG than RBD PO, EDIE PO required significantly higher energy than RBD PO to melt its TAG components completely. That is because EDIE PO had a higher amount of $S_{3}$ TAG, which absorbed a large amount of energy to bring them to a complete melt. The higher $\Delta \mathrm{H}_{\mathrm{i}^{\circ} \mathrm{C}}$ values in the lower melting region below $0^{\circ} \mathrm{C}$ showed that the low melting TAG component of EDIE PO also absorbed more energy than that of RBD PO, as EDIE PO contained more $\mathrm{U}_{3}$ TAG that melted in that temperature region. In the temperature region below $0^{\circ} \mathrm{C}, 35.3 \%$ of the TAG component of EDIE PO had already melted, compared to only $26.5 \%$ for RBD PO. There were not many changes in $\Delta \mathrm{H}_{\mathrm{i}^{\circ} \mathrm{C}}$ values for EDIE PO in the temperature region of $0^{\circ} \mathrm{C}$ to $30^{\circ} \mathrm{C}$, unlike for $\mathrm{RBD}$ $\mathrm{PO}$, due to the low amount of the TAG component 


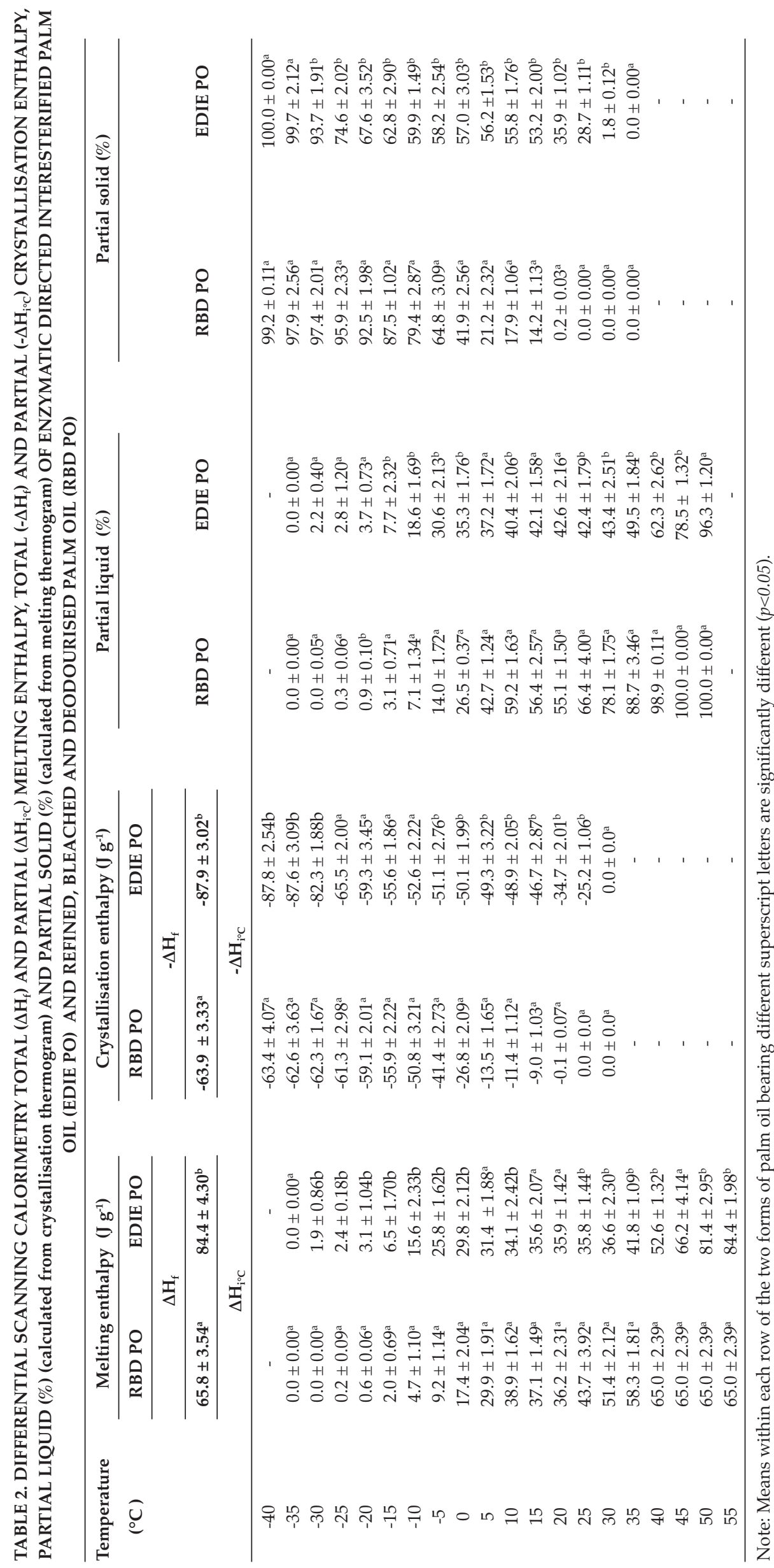


$\left(\mathrm{U}_{2} \mathrm{~S}\right.$ and $\left.\mathrm{S}_{2} \mathrm{U}\right)$ that melted in that temperature region. RBD PO experienced a significant increase in $\Delta \mathrm{H}_{\mathrm{i}^{\circ} \mathrm{C}}$ values in the temperature region of $0^{\circ} \mathrm{C}$ to $10^{\circ} \mathrm{C}$, most probably because of the melting of $\mathrm{U}_{2} \mathrm{~S}$ type TAG. A decline in $\Delta \mathrm{H}_{\mathrm{i}^{\circ} \mathrm{C}}$ values was observed in the temperature region of $10^{\circ} \mathrm{C}$ to $20^{\circ} \mathrm{C}$; most probably because of polymorphic changes that resulted in crystallisation of some of the TAG component that released heat during the heating process in that temperature region. Due to the heat release upon melting, the liquid TAG component in RBD PO also decreased from $59.3 \%$ at $10^{\circ} \mathrm{C}$ to $55.1 \%$ at $20^{\circ} \mathrm{C}$. In the temperature region of $25^{\circ} \mathrm{C}$ to $40^{\circ} \mathrm{C}$, the energy absorbed by EDIE PO was significantly lower than that absorbed by RBD PO. That is because RBD PO contains a higher amount of solid $S_{2} U$ TAG that melt in this temperature region than EDIE PO. In the temperature region above $40^{\circ} \mathrm{C}$, the TAG component of EDIE PO absorbed significantly more energy than RBD PO, as EDIE PO contained a much higher amount of $S_{3}$ TAG. This observation is in line with the findings of Tan and Che' Man (2002), who demonstrated that more energy is needed to melt an oil that contains high amounts of long-chain saturated TAG.

Crystallisation properties of oils and fats, e.g., crystal habit, crystal size and crystal number, indirectly influence the physical properties of the end-products. Crystallisation properties, in turn, largely depend on the chemical composition of a particular oil or fat, e.g., the type of FA and the FA position on the TAG molecules (Zhang et al., 2013). A DSC crystallisation curve of an oil or fat often has multiple exothermic peaks which are less complicated than its corresponding melting curve. The crystallisation curve can be subdivided into various exothermic regions, with each region associated with the various types of TAG. The higher melting TAG component will crystallise first; thus, the exothermic peak will appear in the high temperature region. Once the higher melting TAG component has completely crystallised, the lower melting TAG component will enter into the crystallisation process until all TAG components of the oil sample have crystallised, with the exothermic peak appearing in the low temperature region (Tan and Che' Man, 2002). Figure $2 b$ illustrates the DSC crystallisation thermograms of EDIE PO and RBD PO. The thermogram of RBD PO exhibits two distinct exothermic peaks, i.e., one sharp peak at the high $\left(>10^{\circ} \mathrm{C}\right)$ and one broad peak at the low $\left(<10^{\circ} \mathrm{C}\right)$ temperature regions, corresponding to the crystallisation of its major TAG components, the high and low melting TAG, respectively. This finding is in agreement with that of Busfield and Proschogo (1990). The high melting component of RBD PO which comprises mainly $S_{2} U$ and some $S_{3}$ TAG exhibited rapid crystallisation, as depicted by the sharp crystallisation peak with initial and complete crystallisation temperatures of $21^{\circ} \mathrm{C}$ and $12^{\circ} \mathrm{C}$, respectively. The sharp and narrow exothermic peak indicates that crystallisation of the high melting TAG mixture proceeded interactively, and this is probably due to the presence of a highly homogeneous TAG component (Tan and Che' Man, 2002). The low melting TAG component, comprising mainly $\mathrm{U}_{2} \mathrm{~S}$ and a small amount of $U_{3}$ TAG, crystallised over a wide temperature range, with initial and complete crystallisation temperatures of about $-5.5^{\circ} \mathrm{C}$ and $-34^{\circ} \mathrm{C}$, respectively. The broad crystallisation peak is due to a wide TAG distribution (Liu et al., 2010).

The thermogram of EDIE PO exhibits three distinct exothermic peaks, two at the high $\left(>10^{\circ} \mathrm{C}\right)$ and one at the low $\left(<-10^{\circ} \mathrm{C}\right)$ temperature regions. The sharp exothermic peak of EDIE PO with an initial crystallisation temperature of $31^{\circ} \mathrm{C}$ and complete crystallisation temperature of $24^{\circ} \mathrm{C}$ is most probably due to the rapid crystallisation of the very high melting $S_{3}$ TAG which were present in high amounts in EDIE PO. A broader peak with initial and complete crystallisation temperatures of $24^{\circ} \mathrm{C}$ and $8.5^{\circ} \mathrm{C}$ may be due to the crystallisation of $\mathrm{S}_{2} \mathrm{U}$ and $\mathrm{U}_{2} \mathrm{~S}$ TAG which also existed in quite large amounts. Another exothermic peak of EDIE PO, which is not present in the thermogram of RBD PO, shows crystallisation in the temperature region of $-18^{\circ} \mathrm{C}$ to $-38^{\circ} \mathrm{C}$, corresponding to the crystallisation of the low melting $\mathrm{U}_{3}$ TAG, which were present in substantial amounts in EDIE PO.

EDIE PO had significantly $(p<0.05)$ higher crystallisation enthalpy (the energy to transform from a liquid state into a solid state) than RBD PO (Table 2), as EDIE PO had a higher content of $S_{3}$ TAG (particularly PPP) than RBD PO which had more $\mathrm{S}_{2} \mathrm{U}$ (particularly POP) and $\mathrm{U}_{2} \mathrm{~S}$ (particularly POO) TAG. This finding is in agreement with that of Da Silva et al. (2017) who stated that the crystallisation enthalpy of PPP is high, i.e., $66.99 \mathrm{~J} \mathrm{~g}^{-1}$. The $-\Delta \mathrm{H}_{\mathrm{i}^{\circ} \mathrm{C}}$ values suggest that EDIE PO started to release energy to initiate crystallisation earlier than RBD PO. This can be explained by its high content of $\mathrm{S}_{3}$ TAG. For instance, about $-25.2 \mathrm{~J} \mathrm{~g}^{-1}$ or $28.7 \%$ of crystallisation energy was released from EDIE PO when the crystallisation temperature dropped from $30^{\circ} \mathrm{C}$ to $25^{\circ} \mathrm{C}$, corresponding to crystallisation of its $\mathrm{S}_{3}$ TAG. RBD PO did not release any energy in the same temperature range as none of its TAG had yet to crystallise. Additionally, EDIE PO released about $40 \%$ more energy in the temperature range of $-10^{\circ} \mathrm{C}$ to $-40^{\circ} \mathrm{C}$, which corresponded to crystallisation of its $\mathrm{U}_{3}$ TAG. Most of the crystallisation energy of RBD PO (about $64.9 \%$ or $-42.4 \mathrm{~J} \mathrm{~g}^{-1}$ ) was released in the temperature range of $5^{\circ} \mathrm{C}$ to $-15^{\circ} \mathrm{C}$, which most certainly corresponded to crystallisation of its $\mathrm{S}_{2} \mathrm{U}$ and $\mathrm{U}_{2} \mathrm{~S}$ TAG.

The DSC partial solid at various crystallisation temperatures for EDIE PO and RBD PO presented in Table 2 show that EDIE PO crystallised much faster 
than RBD PO in the temperature region of $30^{\circ} \mathrm{C}$ to $20^{\circ} \mathrm{C}$, due to crystallisation of its $\mathrm{S}_{3}$ TAG. RBD PO showed rapid and almost complete crystallisation in the temperature region of $15^{\circ} \mathrm{C}$ to $-20^{\circ} \mathrm{C}$, indicating that most of its TAG $\left(\mathrm{S}_{2} \mathrm{U}\right.$ and $\left.\mathrm{U}_{2} \mathrm{~S}\right)$ crystallised in this region. There was not much of an increase in the percentage of solid for EDIE PO in this region as it contained a low amount of $\mathrm{S}_{2} \mathrm{U}$ and $\mathrm{U}_{2} \mathrm{~S}$ TAG. Conversely, EDIE PO showed a rapid increase in the percentage of solid in the temperature region below $-20^{\circ} \mathrm{C}$, indicating that it contained a high amount of $\mathrm{U}_{3}$ TAG. It has previously been established that $\mathrm{U}_{3}$ TAG crystallise in a very low-temperature region (Bahadi et al., 2016).

\section{SFC and SMP}

SFC is an important index used to measure the amount of solid fats at a particular temperature. SFC is responsible for the end-product characteristics, such as physical appearance, ease of packing, spreadability, oil exudation and organoleptic properties of fat-based products (Krawczyk et al., 1996). SFC also determines compatibility between fats by elucidating the alteration in percentage of solids at various fat proportions. The outcome is a graphical indication of the loss of solids as a result of dilution of existing solids with liquid oil, or of incompatibility due to eutectic interaction (Bigalli, 1988). Melting point, or in this study SMP of a fat, is the temperature at which a solid fat becomes liquid oil (Hidalgo and Zamora, 2006). SFC and melting point of a fat are affected by its FA chain length and composition, the ratio of saturation and unsaturation, the complexity of the TAG components and the FA position on the glycerol backbone (Rasor and Duncan, 2014).

An alteration in the TAG composition of PO following EDIE significantly increased its SFC, especially in the temperature region above $15^{\circ} \mathrm{C}$ (Figure 3), and SMP. SMP of EDIE PO and RBD $\mathrm{PO}$ was $52.2^{\circ} \mathrm{C}$ and $38.5^{\circ} \mathrm{C}$, respectively. The higher SFC and SMP values of EDIE PO than those of RBD PO were due to the increase in high melting TAG content, particularly $S_{3}$ TAG (PPP and PPS), following EDIE, while RBD PO was high in medium $\left(\mathrm{S}_{2} \mathrm{U}\right.$, mainly $\mathrm{POP}$ ) and low melting ( $\mathrm{U}_{2} \mathrm{~S}$, mainly POO) TAG. The melting points of PPP and PPS TAG in their $\alpha, \beta^{\prime}$ and $\beta$ polymorphic forms are at $45.0^{\circ} \mathrm{C}$, $56.6^{\circ} \mathrm{C}$ and $66.1^{\circ} \mathrm{C}$, and at $47.4^{\circ} \mathrm{C}, 50.9^{\circ} \mathrm{C}$ and $62.9^{\circ} \mathrm{C}$, respectively. The melting points of $\mathrm{POP}$ and $\mathrm{POO}$ TAG in their $\alpha, \beta^{\prime}$ and $\beta$ polymorphic forms are at $18.1^{\circ} \mathrm{C}, 30.5^{\circ} \mathrm{C}$ and $35.3^{\circ} \mathrm{C}$, and at $-4.0^{\circ} \mathrm{C}, 2.5^{\circ} \mathrm{C}$ and $19.2^{\circ} \mathrm{C}$, respectively (Hidalgo and Zamora, 2006).

\section{Polymorphic Behaviour and Microstructure}

Understanding the morphology of fat crystals is importantfor practical applications. The morphology of fat crystals determines the suitability of the fat for a given purpose. Many factors influence the polymorphic behaviour of a fat, most particularly the way in which the fat is cooled from the melt such as the cooling and agitation rate, as well as the FA and TAG composition of the fat (Martini et al., 2002). The X-ray diffraction is the most widely used method for studying lipid polymorphism. Typical X-ray diffraction patterns of fats exhibit two

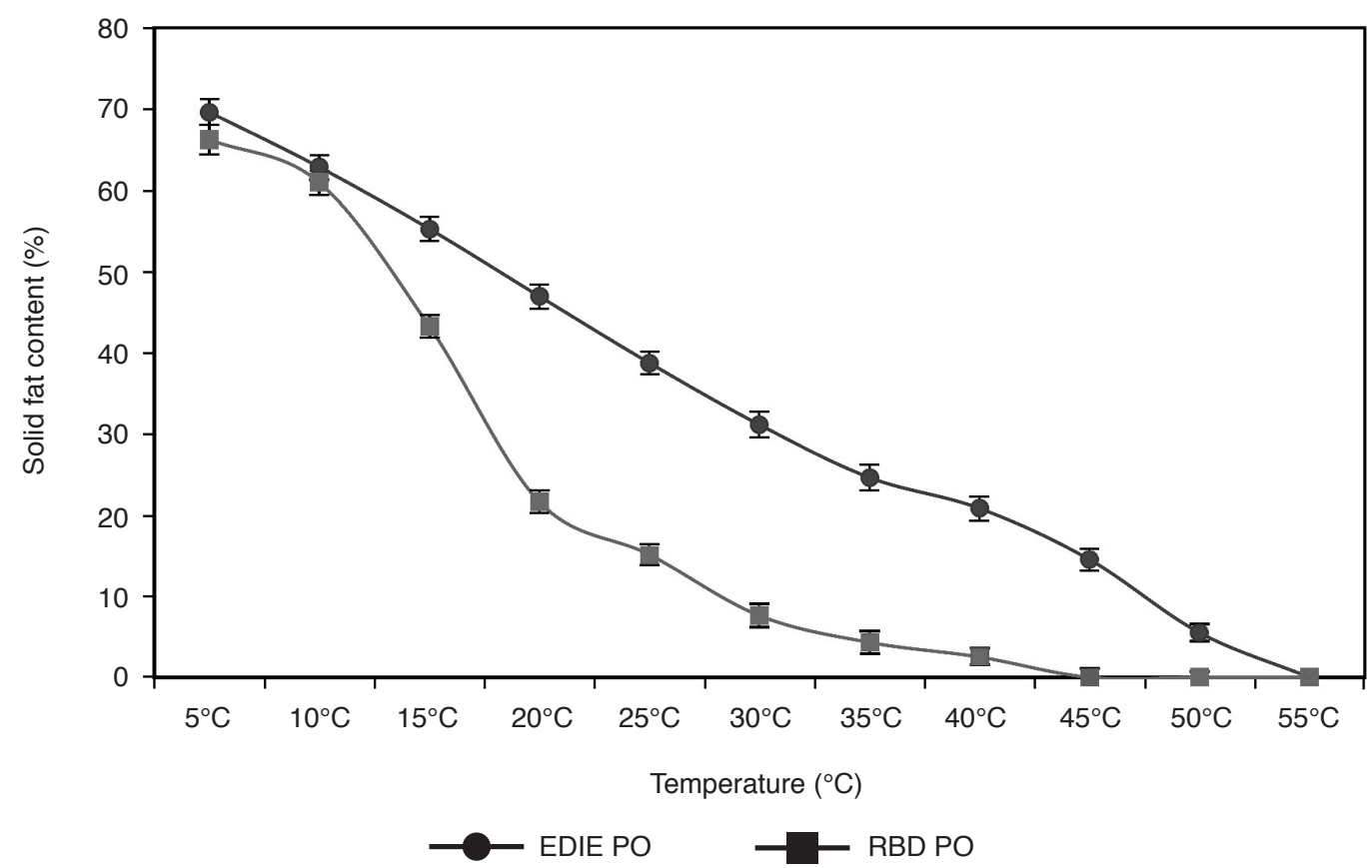

Figure 3. Solid fat content profiles of enzymatic directed interesterified palm oil (EDIE PO) and refined, bleached and deodourised palm oil (RBD PO). 
groups of diffraction lines corresponding to long and short spacings. Short spacings are used mainly to characterise the various polymorphic forms of the fats, namely $\alpha, \beta$ and $\beta^{\prime}$. Short spacings are attributed to the cross-sectional packing of the hydrocarbon chains (Zhang et al., 2013). The least stable $\alpha$ form, which has the lowest melting polymorph, will transform to the $\beta^{\prime}$ form (which has intermediate stability and melting point) before being further changed into the $\beta$ form, the most stable polymorph with the highest melting point (Chong et al., 2007).

The X-ray diffraction crystallography and the polymorphic crystal forms of EDIE PO and RBD PO at storage and determination temperatures of $5^{\circ} \mathrm{C}$, $10^{\circ} \mathrm{C}, 15^{\circ} \mathrm{C}, 20^{\circ} \mathrm{C}$ and $25^{\circ} \mathrm{C}$ are shown in Figure 4 and Table 3, respectively. The dominant polymorph of RBD PO stored at $5^{\circ} \mathrm{C}$ and $10^{\circ} \mathrm{C}$ was almost purely $\beta^{\prime}$. According to Toro-Vazquez et al. (2000), RBD PO that is high in POP TAG tends to generate strong $\beta^{\prime}$ polymorphs. However, as the storage temperature rose to $15^{\circ} \mathrm{C}, 20^{\circ} \mathrm{C}$ and $25^{\circ} \mathrm{C}$, the relative content of $\beta$ polymorphs in RBD PO increased, as shown by the emergence of a peak with spacing close to $4.6 \AA$. The higher the storage temperature, the stronger is the intensity of the peak at spacing $4.60 \AA$, because high temperatures instigate the transformation of
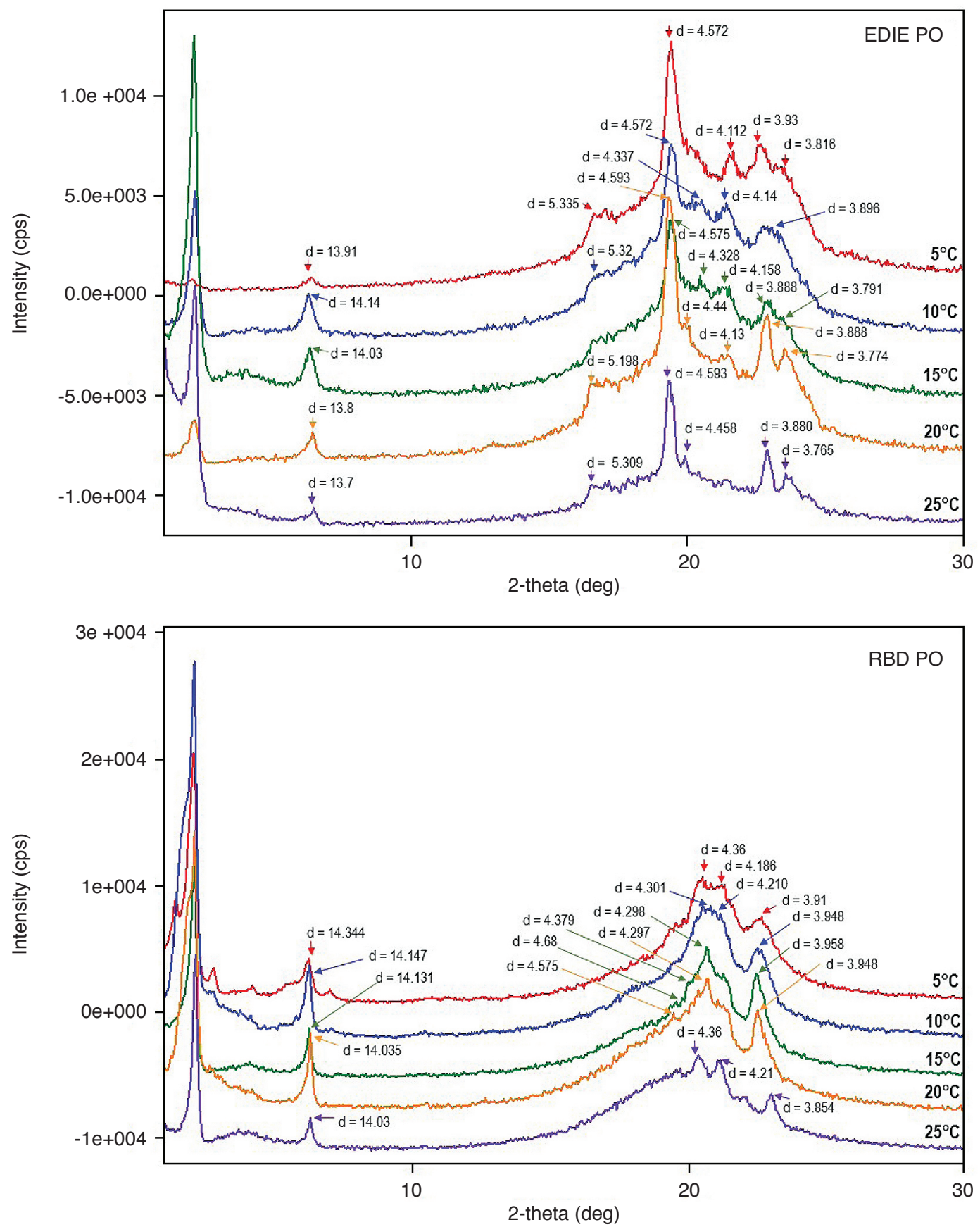

Figure 4. The X-ray diffraction crystallography of enzymatic directed interesterified palm oil (EDIE PO) and refined, bleached and deodourised palm oil (RBD PO) at various storage and determination temperatures. 
TABLE 3. CRYSTAL POLYMORPHIC FORMS OF ENZYMATIC DIRECTED INTERESTERIFIED PALM OIL (EDIE PO) AND REFINED, BLEACHED AND DEODOURISED PALM OIL (RBD PO) AT VARIOUS STORAGE AND DETERMINATION TEMPERATURES

\begin{tabular}{ccc}
\hline \multirow{2}{*}{$\begin{array}{c}\text { Storage and determination } \\
\text { temperature }\left({ }^{\circ} \mathrm{C}\right)\end{array}$} & \multicolumn{2}{c}{ Polymorphic form } \\
\cline { 2 - 3 } & EDIE PO & RBD PO \\
\hline 5 & $\beta>>\beta^{\prime}$ & $\beta^{\prime}>>>>\beta$ \\
10 & $\beta>>\beta^{\prime}$ & $\beta^{\prime}>>>\beta$ \\
15 & $\beta>>\beta^{\prime}$ & $\beta^{\prime}>>>\beta$ \\
20 & $\beta>>>\beta^{\prime}$ & $\beta^{\prime}>>\beta$ \\
25 & $\beta>>>\beta^{\prime}$ & $\beta^{\prime}>\beta$ \\
\hline
\end{tabular}

the POP polymorphs from the metastable $\beta^{\prime}$ to the stable $\beta$ form. As storage temperature increased, the degree of transformation of POP TAG from $\beta^{\prime}$ to stable $\beta$ also increased. This transformation from metastable $\beta^{\prime}$ to stable $\beta$ at high temperature may be because a higher storage temperature provides the energy required for the polymorphic transition as suggested by Shiota et al. (2011). The $\beta^{\prime}$ form with small crystals of RBD PO is desirable for providing good texture and properties in fat-based products such as most margarines and shortenings (Zhu et al., 2017). EDIE PO stabilised in a mixture of $\beta$ and $\beta^{\prime}$ crystals with $\beta$ polymorphs dominating at all storage temperatures, as shown by the strong intensity of peaks close to $4.6 \AA$ for $\beta$ crystals, and weaker intensity of peaks at 4.2 and $3.8 \AA$ for $\beta^{\prime}$. The intensity of the peak at $4.6 \AA$ was remarkably high, especially at storage temperatures of $20^{\circ} \mathrm{C}$ and $25^{\circ} \mathrm{C}$. This observation indicates that the relative content of $\beta$ polymorphs increased following a rise in storage temperature and that the transformation rate from the unstable $\beta^{\prime}$ into the stable $\beta$ polymorphs was higher when the fat was kept at high storage temperature. Stabilisation of EDIE PO with $\beta$ crystals dominating was to be expected as it is rich in $\mathrm{S}_{3}$ TAG (PPP), which stabilised in the $\beta$ form upon storage, in agreement with findings by Bhaggan et al. (2018) and Zhang et al. (2013). The EDIE $P O$ which was $\beta$ stable has a high melting point. According to ADM (2018), high melting fats are suitable to be used as coating agents for ingredients and additives, stabiliser or crystallisation agent for oil-rich products, e.g., peanut butter and spreads, texturisers for shortenings and liquid margarine, and plasticiser in confectionery.

The polymorphic behaviour of RBD PO and EDIE PO is harmonious with their crystal morphology (Figure 5). At low temperatures $\left(5^{\circ} \mathrm{C}-15^{\circ} \mathrm{C}\right)$, RBD PO crystallised into very fine spherulite-shaped crystals, showing the dominance of $\beta^{\prime}$ crystals. At higher stabilisation temperatures $\left(20^{\circ} \mathrm{C}-25^{\circ} \mathrm{C}\right)$, small and loose plate-like crystals were observed with the disappearance of the spherulite-shaped $\beta^{\prime}$ crystals, showing an increase in the amount of $\beta$ crystals. On the other hand, at all stabilisation temperatures, from $5^{\circ} \mathrm{C}-25^{\circ} \mathrm{C}$, EDIE PO crystallised into crystal aggregates with a dense, coarse plate-like and orderly packed structure, showing the occurrence of a high concentration of $\beta$ crystals. These findings are coherent with that of Da Silva et al. (2017), Zhu et al. (2017), Zhang et al. (2014), Ribeiro et al. (2009) and Shin et al. (2009).

\section{CONCLUSION}

EDIE can be considered as a mild and 'green' approach in oils and fats modification. Rearrangement of the FA distribution in the TAG molecules of $\mathrm{PO}$, as a result of EDIE, caused a significant increase in $\mathrm{U}_{3}$ and $\mathrm{S}_{3}$ TAG at the expense of $\mathrm{S}_{2} \mathrm{U}$ and $\mathrm{U}_{2} \mathrm{~S}$ TAG. This increase in $\mathrm{U}_{3}$ and $\mathrm{S}_{3}$ TAG, in turn, modified the physical characteristics of PO. The rise in $\mathrm{U}_{3}$ TAG increased the proportion of the low melting fraction of $\mathrm{PO}$ as depicted by the larger endothermic and exothermic peaks in the very low temperature region, and the shift of endothermic and exothermic peaks towards the lower melting region, as reflected by the DSC melting and crystallisation curves. The elevation of $\mathrm{S}_{3}$ TAG resulted in a higher proportion of the high melting fraction of $\mathrm{PO}$, as reflected by the larger DSC endothermic peak in the high temperature region, the DSC endothermic peak shifting towards the high temperature region, the higher proportion of solid fat in the high temperature region, the higher SMP, and higher proportions of $\beta$ polymorphs and coarser crystals. In all, EDIE can be considered as one of the methods of choice to increase $\mathrm{U}_{3}$ and $\mathrm{S}_{3}$ TAG in RBD PO. This process is essential especially when further fractionation is to be carried out to separate the olein fraction high in oleic acid from the stearin fraction high in palmitic acid for use as a high oleic oil and as a trans-free structural fat, respectively.

\section{ACKNOWLEDGEMENT}

The authors acknowledge MPOB for its financial support of this research and Director-General for permission to publish this article. The authors also acknowledge Isham Ismail, Mohamad Adrina Malik, Hanirah Hassan, Siti Hazirah Mohd Fauzi and Roziah Ahmad of MPOB for their contribution in ensuring the success of this study. 

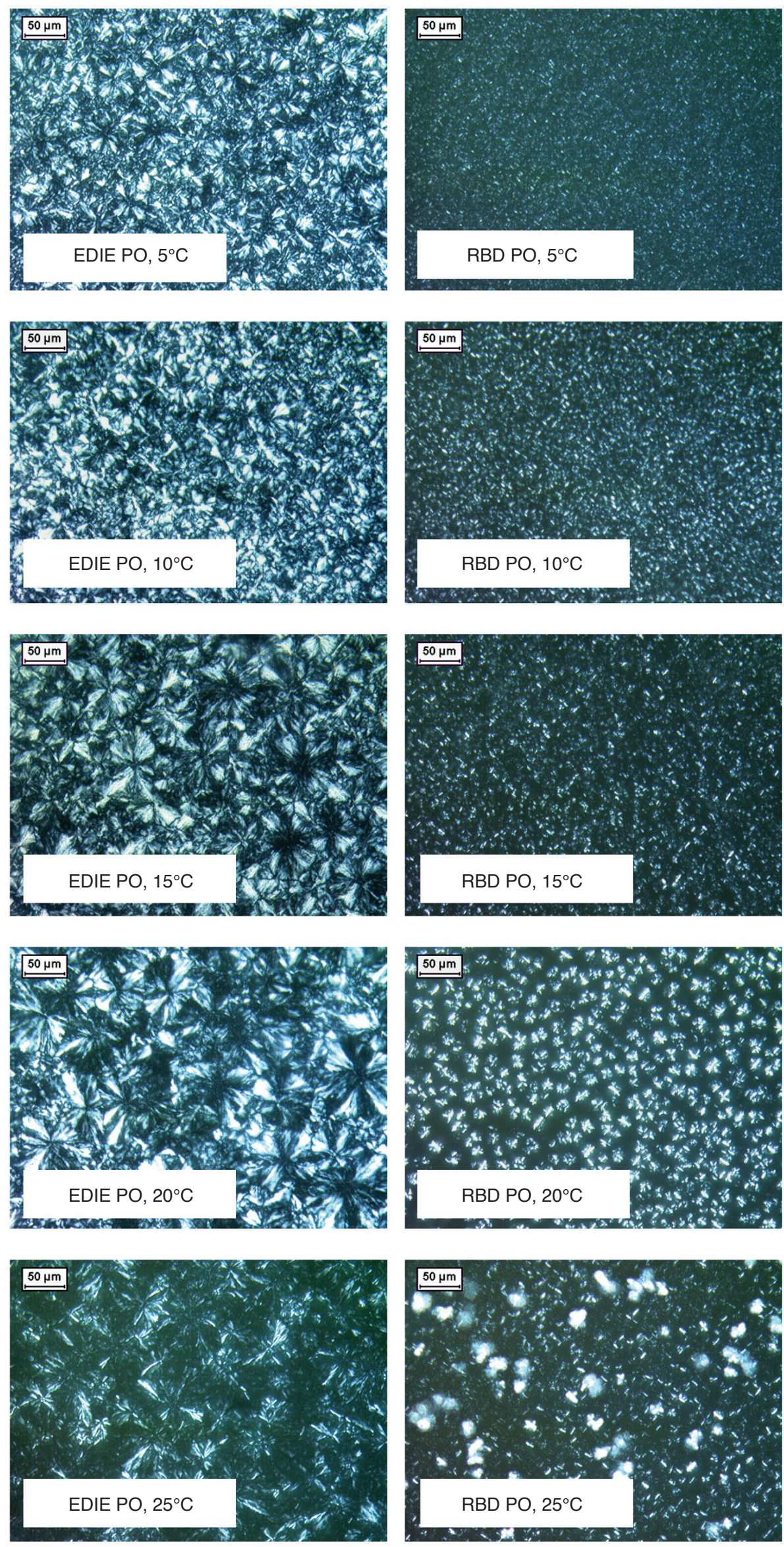

Figure 5. Microstructural images (at 200X magnification) under a polarised light microscope of enzymatic directed interesterified palm oil (EDIE PO) and refined, bleached and deodourised palm oil (RBD PO) at stabilisation (24 hr) and various determination temperatures. 


\section{REFERENCES}

Archer Daniels Midland (ADM) (2018). High melting point solid vegetable oils. https:/ / www. adm.com/adm-worldwide/japan/products / highmelting-point-solid-vegetable-oils, accessed on 12 September 2018.

Ali, A R M and Dimick, P S (1994). Thermal analysis of palm mid-fraction, cocoa butter and milk fat blends by differential scanning calorimetry. J. Amer. Oil Chem. Soc., 71: 299-302.

Amir, R A; Shabbir, M A; Khan, M R and Hussain, S (2012). Interesterification of fats and oils - A review. Pakistan J. Food Sci., 22: 143-153.

Bahadi, M A; Salimon, J and Japir, A W M (2016). The physicochemical and thermal properties of Malaysian high free fatty acid crude palm oil. AIP Conference Proceedings. Vol. 1784. AIP Publishing, New York, USA. p. 030002.

Baur, F J and Lange, W (1951). Directed interesterification in glycerides. III. The synthesis of single-fatty acid 1,3-diglycerides. J. Amer. Oil Chem. Soc., 73: 3926-3928.

Bhaggan, K; Smith, K W; Blecker, C and Danthine, $S$ (2018). Binary mixtures of tripalmitoylglycerol (PPP) and 1,3-dipalmitoyl-2-stearoyl-sn-glycerol (PSP): Polymorphism and kinetic phase behavior. Eur. J. Lipid Sci. Technol., 120: 1700306.

Bigalli, G L (1988). Practical aspects of the eutectic effect on confectionery fats and their mixtures. Manuf. Confect., 68: 65-80.

Busfield, W K and Proschogo, P N (1990). Thermal analysis of palm stearin by DSC. J. Amer. Oil Chem. Soc., 67: 171-175.

Chobanov, D G and Topalova, M R (1979). Alterations in glyceride composition during directed interesterification of lard. J. Amer. Oil Chem. Soc., 56: 581-584.

Chong, C L; Kamarudin, Z; Lesieur, P; Marangoni, A; Bourgaux, C and Ollivon, M (2007). Thermal and structural behaviour of crude palm oil: Crystallisation at very slow cooling rate. Eur. J. Lipid Sci. Technol., 109: 410-421.

De Lathauwer, R; Van Opstal, M and Dijkstra, A J (1983). Process for the directed interesterification of a triglyceride oil or oil mixture and triglyceride oils or oil mixture thus interesterified. US patent $4,419,291$
D'Souza, V; Deman, J M and Deman, L (1990). Short spacings and polymorphic forms of natural and commercial solid fats: A review. J. Amer. Oil Chem. Soc., 67: 835-843.

Da Silva, R C; Soares, F A S D M; Maruyama, J M; Dagostinho, N R; Silva, Y A; Ract, J N R and Gioielli, L A (2017). Crystallisation of monoacylglycerols and triacylglycerols at different proportions: Kinetics and structure. Int. J Food Prop., 20: S385-S398.

Firestone, D (2009). Official Methods and Recommended Practices of the AOCS. $6^{\text {th }} \mathrm{ed}$. AOCSPress, Champaign, IL, USA.

Frederick, E; Foubert, I; De Sype, J V and Dewettinck, $K$ (2008). Influence of monoglycerides on the crystallization behavior of palm oil. Cryst. Growth Des., 8: 1833-1839.

Hidalgo, F J and Zamora, R (2006). Fats: Physical properties. Handbook of Food Science, Technology, and Engineering (Hui, Y H ed.). Vol. 1. CRC Press, Florida, USA. p. 9-1-9-27.

International Organisation for Standardisation (IOS) (1990). ISO 5508:1990(E). Animal and Vegetable Fats and Oils - Analysis by Gas Chromatography of Methyl Esters of Fatty Acids. $2^{\text {nd }}$ ed. International Organization for Standardization, Geneva, Switzerland.

Krawczyk, G R; Buliga, G S; Bertrand, D T and Humphreys, W M (1996). Reviewing the technology of low fat spreads. Inform, 7: 635-639.

Lago, R C A and Hartman, L (1986). Directed interesterification of a Brazilian palm oil and analysis of the original and interesterified oil and its fractions. J. Sci. Food Agric., 37: 689-693.

Laning, S J (1985). Chemical interesterification of palm, palm kernel and coconut oils. J. Amer. Oil Chem. Soc., 62: 400-407.

Liu, Y; Meng, Z; Shan, L; Jin, Q and Wang, X (2010). Preparation of specialty fats from beef tallow and canola oil by chemical interesterification: Physicochemical properties and bread applications of the products. Eur. Food Res. Technol., 230: 457-466.

Mackenzie, A D and Stevenson, D E (2000). Production of high-oleic acid tallow fractions using lipase-catalyzed directed interesterification, using both batch and continuous processing. Enzyme Microb. Technol., 27: 302-311.

Mackenzie, A D and Stevenson, D E (1995). Modification of the nutritional properties of fats 
using lipase catalysed directed interesterification. Biotechnol. Lett., 17: 383-388.

MPOB (2004). MPOB Test Methods - A Compendium of Tests on Palm Oil Products, Palm Kernel Products, Fatty Acids, Food-related Products and Others. MPOB, Bangi.

Malaysian Standard (MS) (2003). MS 817: Part 9: Section 1:2003. Methods of Test for Palm Oil and Palm Oil Products: Part 9: Determination of Solid Fat Content by Pulsed Nuclear Magnetic Resonance (PNMR): Section 1: Direct Method. Malaysian Standard.

Marangoni, A G and Rousseau, D (1995). Engineering triacylglycerols: The role of interesterification. Trends Food Sci. Technol., 6: 329-335.

Martini, S; Herrera, M L and Hartel, R W (2002). Effect of processing conditions on microstructure of milk fat fraction/sunflower oil blends. J. Amer. Oil Chem. Soc., 79: 1063-1068.

Nassu, R T and Goncalves, L A G (1999). Determination of melting point of vegetable oils and fats by differential scanning calorimetry (DSC) technique. Grasas Y Aceites, 50: 16-21.

Nugrahini, A D and Soerawidjaja, T H (2015). Directed interesterification of coconut oil to produce structured lipid. Agric. Agric. Sci. Procedia, 3: 248254.

Placek, C and Holman, G W (1957). Directed interesterification of lard. J. Ind. Eng. Chem., 49: 162169.

Rasor, A S and Duncan, S E (2014). Fats and oils - Plant based. Food Processing: Principles and Applications (Clark, S; Jung, S and Lamsal, B eds.). Wiley-Blackwell, New Jersey, USA. p. 457-477.

Ribeiro, A P B; Basso, R C; Grimaldi, R; Gioielli, L A; Dos Santos, A O; Cardoso, L P and Goncalves, L A G (2009). Influence of chemical interesterification on thermal behavior, microstructure, polymorphism and crystallization properties of canola oil and fully hydrogenated cottonseed oil blends. Food Res. Int., 42: 1153-1162.

Rousseau, D and Marangoni, A G (2008). Chemical interesterification of food lipids: Theory and practice. Food Lipids: Chemistry, Nutrition, and Biotechnology (Akoh, C C and David, B M eds.). CRC Press, Florida, USA. p. 267-292.
Saberi, A H; Lai, O M and Miskandar, M S (2012). Melting and solidification properties of palm-based diacylglycerol, palm kernel olein, and sunflower oil in the preparation of palm-based diacylglycerolenriched soft tub margarine. Food Bioprocess Tech., 5: 1674-1685.

Saw, M H; Hock, C C and Siew, W L (2009). Characterization of low saturation palm oil products after continuous enzymatic interesterification and dry fractionation. J. Food Sci., 74: E177-E183.

Shiota, M; Iwasawa, A; Kotera, M; Konno, M; Isogai, T and Tanaka, L (2011). Effect of fatty acid composition of monoglycerides and shear on the polymorph behavior in water-in-palm oil-based blend. J. Am. Oil Chem. Soc., 88: 1103-1111.

Shin, J A; Akoh, C C and Lee, K T (2009). Production and physicochemical properties of functionalbutterfat through enzymatic interesterification in a continuous reactor. J. Agric. Food Chem., 57: 888-900.

Szydłowska-Czerniak, A; Karlovits, G; Lach, M and Szłyk, E (2005). X-ray diffraction and differential scanning calorimetry studies of $\beta^{\prime} \rightarrow \beta$ transitions in fat mixtures. Food Chem., 92: 133-141.

Tan, C P and Che' Man, Y (2002). Differential scanning calorimetric analysis of palm oil, palm oilbased products and coconut oil: Effects of scanning rate variation. Food Chem., 76: 89-102.

Toro Vazquez, J F; Briceno Montelongo, M; Dibildox Alvarado, E; Charo Alonso, M and Reyes Hernández, J (2000). Crystallization kinetics of palm stearin in blends with sesame seed oil. J. Amer. Oil Chem. Soc., 77: 297-310.

Zhang, X; Li, L; Xie, H; Liang, Z; Su, J; Liu, G and LI, B (2014). Effect of temperature on the crystalline form and fat crystal network of two model palm oil-based shortenings during storage. Food Bioprocess Tech., 7: 887-900.

Zhang, X; Li, L; Xie, H; Liang, Z; Su, J; Liu, G and LI, B (2013). Comparative analysis of thermal behavior, isothermal crystallization kinetics and polymorphism of palm oil fractions. Molecules, 18: 1036-1052.

Zhu, T; Zhao, Y; Zong, M; Li, B; Zhang, X and Wu, $H$ (2017). Improvement of physical properties of palm stearin and soybean oil blends by enzymatic interesterification and their application in fast frozen food. RSC Advances, 7: 34435-34441. 